\title{
The Effects of Starvation and
} Refeeding on Oxidative Stress Parameters (MDA, SOD, GPX), Lipid Profile, Thyroid Hormones and Thyroid Histopathology in Male Wistar Rats

\section{Abstract}

Objective: This study aimed to investigate the effect of starvation and re-feeding on oxidative stress markers, lipid profile, thyroid hormones, and changes in thyroid tissue and in male Wistar rats.

Method: Fifty-six male Wistar rats were divided into 6 groups. After 3 months of feeding animals with specific diet, the first group was used without fasting (day zero). Other rats were exposed to fasting for 14 days. The second group was considered as a group after fasting (day 14). In groups 3 to 6 , replenishment was done and then these groups were euthanized on days 16 to 22 , and blood and tissue samples were taken.

Results: Significant increase was observed in MDA, triglycerides, and VLDL cholesterol. The concentrations of SOD, GPx and T3 were decreased significantly. By re-feeding, SOD, GPx, triglycerides, total cholesterol, and VLDL cholesterol increased. T3 concentration was significantly increased in all groups after re-feeding. In thyroid tissue, the diameter of follicles and the amount of colloid decreased and the number of parafollicular cells increased during starvation. By days 2 and 4 post-refeeding there were follicles with different sizes and the numbers of parafollicular cells were increased. 
Conclusion: Starvation may act on the depletion of antioxidants, predisposing subjects to oxidative injury highlights with enhanced level of MDA. Oxidative stress, may play a critical role in the pathophysiology of starvation- refeeding syndrome. Starvation results in a decrease in the serum T3 concentration due to decreased peripheral generation of T3 from T4, because carbohydrates are major regulators of T4 deiodination. The increased free fatty acid availability to the circulation and eventually to the liver contribute to increased VLDL synthesis and elevated plasma triglyceride levels after starvation. The negative effects of oxidative stress in considerable time after re-feeding should be considered in future studies.

\section{Introduction}

Starvation-refeeding syndrome as an unusual multisystem disorder may occur as a consequence of refeeding after a prolonged starvation period [1]. In the starvation-refeeding syndrome, the body encounters two distinct conditions. In the starvation status, the body shifts from carbohydrate to fat and protein utilization to produce glucose and energy. In the refeeding status, the body shifts back instantaneously to carbohydrate metabolism [2-4]. Studies on anorexia nervosa patients and fish species showed that the starvation period has prooxidant effects due to both increased lipid peroxidation levels and the reduced level of antioxidant defenses [5-8]. Capability of refeeding in anorexia nervosa patients for reducing the oxidative stress or increasing the levels of antioxidant markers is unknown. An increase in fat mass during refeeding may be associated with higher oxidative stress [7]. Oxidative stress is a multi-factorial process involving numerous metabolic pathways in the cells. Thyroid hormones play a significant role in oxidative stress due to their capacity to accelerate the basal metabolism, cellular reactions and changing respiratory rate in mitochondria [9]. Thyroid hormones affect the cell antioxidant mechanisms in different ways.
There is a complex and controversial relationship between thyroid hormone levels and oxidative stress. Hypometabolic state in hypothyroidism may protect tissues from oxidative stress or in a reverse manner, hypothyroidism may increase the oxidative stress $[10,11]$. Some authors stated that, elevated levels of thyroid hormones encounter body with oxidative stress, whereas reduced thyroid hormone levels result in undetectable to mild oxidative stress [12]. According to what has been mentioned, some questions remain to be elucidated in the relationships between oxidative stress, thyroid hormones, and lipid metabolism during starvation-refeeding status. This study aimed to investigate the effect of starvation and re-feeding on oxidative stress markers, lipid profile, thyroid hormones, and changes in thyroid tissue and in male Wistar rats.

\section{Methods}

\section{Ethics}

All the procedures involving the rats were agreed on by the Shiraz University Animal Care and Use Committee. Also, recommendations of European Council Directive 86/609/EC (1986) were followed regarding the guidelines for the protection of animals used for experimental purposes. 


\section{Animals and diet}

Fifty-six male Wistar rats were divided into 6 groups of 6 to 11. After 3 months of feeding animals with the mentioned diet, the first group was used without fasting (day zero). Other rats were exposed to fasting for 14 days. The second group was considered as a group after fasting (day 14). In groups 3 to 6 , replenishment was done and these groups were then euthanized on days 16 to 22 , and blood and tissue samples were taken. The animals were housed in cages in a room at a temperature of $22-25^{\circ} \mathrm{C}$ and humidity at $50 \pm 5 \%$ with 12 hour light-dark cycles. Animals were allowed food and water ad libitum before starvation and during the refeeding status. The diet contained 19\% protein, $4.3 \%$ fat, $5 \%$ fiber, and $4 \%$ ash, and metabolizable energy was $2.265 \mathrm{kcal} / \mathrm{kg}$ diet.

\section{Study protocol}

Blood samples were taken via heart puncture with the rats under terminal anesthesia. To minimize influence of circadian changes, all samples were taken between 0930 and $1130 \mathrm{~h}$. Treatments included:

Group 1 ( $n=11$ ): control rats, without starvation and refeeding, (day 0$)$.

Group $2(n=6)$ : rats exactly after starvation, (day 14).

Group $3(n=10)$ : rats with 2 days on refeeding, (day 16).

Group $4(n=10)$ : rats with 4 days on refeeding, (day 18).

Group $5(n=9)$ : rats with 6 days on refeeding, (day 20).

Group 6 ( $n=10)$ : rats with 8 days on refeeding, (day 22).

\section{Biochemical analysis}

After centrifugation of blood at $750 \mathrm{~g}$ for $15 \mathrm{~min}$ at room temperature, serum was separated and stored at $-80{ }^{\circ} \mathrm{C}$ until analysis. The samples with hemolysis were discarded.

\section{Measurement of malondialdehyde (MDA)}

To evaluate lipid peroxidation in blood a modified HPLC method was used which is based on the reaction of malondialdehyde (MDA) with thiobarbituric acid (TBA) to form a colored MDA-TBA adduct. Briefly, $0.5 \mathrm{~mL}$ blood supernatant was added to $2 \mathrm{~mL}$ TBA reagent containing $0.375 \%$ TBA, $15 \%$ trichloroacetic acid and $0.25 \mathrm{~mol} / \mathrm{L} \mathrm{HCl}$. The mixture was immediately heated $\left(60 \mathrm{~min}\right.$ at $95^{\circ} \mathrm{C}$ ) and cooled with running water and thereafter butanol-pyridine $(15: 1, v / v)(1 \mathrm{~mL})$ was added and the final volume was adjusted to $2 \mathrm{~mL}$ with distilled water. After vigorous mixing, the organic layer was separated by centrifugation (16 000 g, 3 minutes, at room temperature). The supernatant was analyzed on a UVvisible spectrophotometer fitted with an $80 \mu \mathrm{L}$ flow cell. The absorbance was measured at $532 \mathrm{~nm}$ (the mobile phase consisted of $300 \mathrm{~mL} / \mathrm{L}$ methanol in 50 mM KH2PO4, pH: 7.0). 1, 1, 3, 3-tetraethoxypropane was used as standard, and MDA-TBA reactive substances values were expressed as Unit per gram of hemoglobin $(\mathrm{U} / \mathrm{gHb})$. The HPLC system consisted of a solvent delivery pump (JASCO 980-PU, Tokyo, Japan), a reversed-phase column (Luna C18, 250 $\mathrm{mm} \times 4.6 \mathrm{~mm}$, Phenomenex, CA, USA), and a UVVis detector (Jasco, UV-975, Tokyo, Japan) operated at $532 \mathrm{~nm}$.

\section{Blood and Hemoglobin Preparation}

The whole blood was centrifuged to remove plasma components. The packed red cells were washed three times in an isotonic saline solution $(0.9 \%$ $\mathrm{NaCl}$ ) and red cells were osmetically lysed with cold distilled water (2cc). Hemoglobin ( $\mathrm{Hb})$ was measured using cyanmethemoglobin method [13].

\section{Superoxide dismutase (SOD) assay}

SOD detection RANSOD kit (Randox lab, Crumlin, United Kingdom) was used to evaluate total SOD activity according to the manufacturer's instructions. The function of SOD is to hasten the dis- 
mutation of the toxic superoxide produced during oxidative energy processes to hydrogen peroxide and molecular oxygen. In this, methodxanthine and xanthine oxidase (XOD) are utilized to generate superoxide radicals which react with 2 -(4-iodophenyl) -3 - (4-nitrophenol) -5-phenyltetra-zolium chloride (INT) to form a red formazan dye. The SOD activity is then measured by the degree of inhibition of this reaction. One unit of SOD is that which causes $50 \%$ inhibition in the rate of reduction of INT under the conditions of the assay. Using a standard curve SOD levels were recorded at $505 \mathrm{~nm}$ and were expressed as unit per gram of hemoglobin ( $\mathrm{U} / \mathrm{g} \mathrm{Hb})$.

\section{Glutathione peroxidase (GPX) assay (GPX)}

The activity of GPx was evaluated with GPx detection RANSEL kit (Randox lab. Crumlin United Kingdom) according to the manufacturer's instructions. GPx catalyze the oxidation of glutathione (GSH) by cumene hydroperoxide. In the presence of glutathione reductase (GR) and nicotinamide adenine dinucleotid phosphate (NADPH), the oxidized glutathione (GSSG) is immediately converted to the reduced form with a concomitant oxidation of $\mathrm{NADPH}$ to NADP+. The decrease in absorbance at $340 \mathrm{~nm}$ against blank was measured spectrophotometrically. One unit $(U)$ of GPX activity was defined as the amount of enzyme that converts $1 \mu \mathrm{mol}$ of $\mathrm{NADPH}$ to NADP+ per minute. The GPX activity was expressed as unit per gram of hemoglobin (U/g).

\section{Measurement of thyroid hormones}

Serum T3 concentrations were determined using a competitive enzyme immunoassay kit (Monobind Inc, Lake Forest, USA). The intra- and inter-assay CVS of the assays were $12.6 \%$ and $13.2 \%$, respectively. The sensitivity of the test was $0.2 \mathrm{ng} / \mathrm{mL}$. Serum thyroxine (T4) concentrations were measured using a competitive enzyme immunoassay kit (Monobind Inc., CA, USA). The intra- and inter-assay CVs of the assays were $3.0 \%$ and $3.7 \%$, respectively. The sensitivity of the test was $0.4 \mathrm{mg} / \mathrm{dL}$.

\section{Measurement of lipid profile (total cholesterol, triglyceride, HDL, LDL, VLDL cholesterol)}

The analysis of the serum for total cholesterol was done using a commercial kit (Ziest Chem Diagnostics, Tehran, Iran) by a modified Abell-Kendall/ Levey-Brodie (A-K) method and the measurement of serum triglyceride was accomplished based on the enzymatic procedure by a commercial kit (Ziest Chem Diagnostics, Tehran, Iran). Lipoproteins including HDL-cholesterol $(\mathrm{mg} / \mathrm{dL})$ and $\mathrm{LDL}$-cholesterol $(\mathrm{mg} / \mathrm{dL})$ were analyzed by quantitative enzymatic colorimetric method using test kits supplied by Ziest Chem Diagnostics, Tehran, Iran. All reactions were measured using Digital UV/VIS Spectrophotometer (CE 292, series 2, Cecil Instruments, Cambridge, England). VLDL-cholesterol was estimated as onefifth of the concentration of triglycerides [14].

\section{Histopathological evaluation}

Thyroid tissues were collected from animals and fixed in $10 \%$ neutral buffered formalin at room temperature. After fixing the tissue, it was thoroughly washed under running water and dehydrated in ascending grades of ethyl alcohol, cleared, and embedded in soft paraffin. Tissue sections of about $5 \mu \mathrm{m}$ were obtained, and stained using hematoxylin and eosin (H\&E) staining method and examined under a light microscope.

\section{Statistical Analysis}

All descriptive statistics are reported as mean \pm SEM. Data were analyzed using SPSS Statistics Version 20.0 for Windows. The significance of the differences between the treatments was established by the ANOVA and $t$ test procedure and using Duncan's multiple range post hoc tests. Significance level was set at $P<0.05$. Finally, Pearson's correlation coefficients were used to examine the interrelations of all physiological parameters (two-tailed significance tests; alpha level: $P \leq 0.05$ ). 
Table 1. Evaluation of the effects of starvation with comparison of the mean \pm SEM of oxidative stress markers in rats before and after starvation.

\begin{tabular}{|c|c|c|c|}
\hline Group $(\mathbf{n}) /$ Variable & MDA (mmol/l) & SOD (u/gHb) & GPX (u/gHb) \\
\hline G1 (11), before starvation & $13.71 \pm 0.067$ & $284.60 \pm 1.013$ & $62.40 \pm 0.65$ \\
\hline G2 (6), after starvation & $14.22 \pm 0.11$ & $255.25 \pm 2.05$ & $52.25 \pm 1.10$ \\
\hline P Value & $P \leq 0.001$ & $P \leq 0.001$ & $P \leq 0.001$ \\
\hline
\end{tabular}

Table 2. Mean \pm SEM of MDA, SOD, and GPX in rats after starvation (G2) and during re-feeding (day 2 (G3), day $4(\mathrm{G} 4)$, day $6(\mathrm{G} 5)$ and day $8(\mathrm{G} 6)$ ).

\begin{tabular}{|c|c|c|c|}
\hline Group & MDA (mmol/l) & SOD (u/gHb) & GPX (u/gHb) \\
\hline G2 (6) & $14.22 \pm 0.11$ & $255.25 \pm 2.05$ & $52.25 \pm 1.10$ \\
\hline G3 (10) & $13.49 \pm 0.06$ & $294.60 \pm 1.01$ & $64.70 \pm 0.59$ \\
\hline G4 (10) & $14.26 \pm 0.070$ & $284.90 \pm 1.058$ & $52.70 \pm 0.53$ \\
\hline G5 (9) & $15.26 \pm 0.07^{\star}$ & $208.00 \pm 1.82$ & $42.22 \pm 0.61$ \\
\hline G6 (10) & $13.240 \pm 0.05^{*}$ & $310.70 \pm 2.16^{*}$ & $69.20 \pm 0.89^{*}$ \\
\hline
\end{tabular}

* Significant difference with group 2 (the effect of re-feeding), $P \leq 0.001$.

\section{Results}

In the present study, the starvation effect was observed with significant increase in the amount of MDA $(P \leq 0.001)$, triglycerides $(P=0.01)$, and VLDL cholesterol ( $P=0.01)$, (Table 1 \& 5) and the concentrations of SOD, GPx and T3 were decreased significantly ( $\mathrm{P} \leq 0.001)$, (Table 1 \& 3). By re-feeding, SOD, GPx, triglycerides, total cholesterol, and VLDL cholesterol increased significantly in the $6^{\text {th }}$ group $(P \leq 0.001)$, (Table 2 \& 6). While the concentration of MDA in the $5^{\text {th }}$ group increased and then decreased in the $6^{\text {th }}$ group due to re-feeding $(P \leq 0.001)$. T3 concentration was significantly increased in all groups after re-feeding ( $\mathrm{P} \leq 0.001)$, (Table 4). Intercorrelations (Pearson's) between evaluated physiological parameters are shown in Table 7.

Histopathological evaluation

No lesions were observed in the tissue sections from the rats of group 1 (without starvation), while
Table 3. Evaluation of the effects of starvation with comparison of the mean \pm SEM of thyroid hormones in rats before and after starvation.

\begin{tabular}{|c|c|c|}
\hline Group $(\mathbf{n}) /$ Variable & T3 (nmol/I) & T4 (nmol/I) \\
\hline G1 (11), before starvation & $2.37 \pm 0.081$ & $42.34 \pm 1.67$ \\
\hline G2 (6), after starvation & $1.27 \pm 0.11$ & $45.55 \pm 1.28$ \\
\hline P Value & $P \leq 0.001$ & NS \\
\hline
\end{tabular}

NS: non-significant

the diameter of follicles and the amount of colloid decreased and the number of parafollicular cells increased in the rats of group 2 (after starvation) (Fig. 1 G2).

By 2 and 4 days post-refeeding follicles with different sizes were seen. Follicles diameter and the 
Table 4. Mean \pm SEM of thyroid hormones in rats after starvation (G2) and during re-feeding (day 2 (G3), day 4 (G4), day 6 (G5) and day $8(\mathrm{G} 6))$.

\begin{tabular}{|c|c|c|}
\hline Group & T3 (nmol/I) & T4 (nmol/l) \\
\hline G2 (6) & $1.27 \pm 0.11$ & $45.55 \pm 1.28$ \\
\hline G3 (10) & $2.38 \pm 0.10 *$ & $43.88 \pm 1.26$ \\
\hline G4 (10) & $2.15 \pm 0.21 *$ & $41.44 \pm 2.05$ \\
\hline G5 (9) & $2.26 \pm 0.11 *$ & $41.69 \pm 0.72$ \\
\hline G6 (10) & $2.50 \pm 0.094^{*}$ & $44.65 \pm 2.44$ \\
\hline
\end{tabular}

* Significant difference with group 2 (the effect of refeeding), $P \leq 0.001$. amount of colloid decreased and the number of parafollicular cells increased in comparison with the first group (Fig. 1 G3). In rats of groups 5 and 6 in comparison with group 2, the severity of the lesion gradually decreased (Figs. 1 G5 and G6).

\section{Discussion}

Malondialdehyde (MDA) is one of the end products of lipid peroxidation. The findings of the present study reveal a significant increase in serum MDA levels after starvation status in rats $(P \leq 0.001)$. Level of MDA is also reported to be increased in rabbits [15] and in several fish species after starvation stress $[16,17]$. Starvation status with pro-oxidant effects

Table 5. Evaluation of the effects of starvation with comparison of the mean \pm SEM of lipid profile in rats before and after starvation.

\begin{tabular}{|c|c|c|c|c|c|}
\hline Group (n) /Variable & $\begin{array}{c}\text { Triglyceride } \\
\text { (mg/dl) }\end{array}$ & $\begin{array}{c}\text { Total } \\
\text { Cholesterol } \\
\text { (mg/dl) }\end{array}$ & $\begin{array}{c}\text { LDL } \\
\text { Cholesterol } \\
(\mathbf{m g} / \mathbf{d l})\end{array}$ & $\begin{array}{c}\text { HDL } \\
\text { Cholesterol } \\
\text { (mg/dl) }\end{array}$ & $\begin{array}{c}\text { VLDL } \\
\text { Cholesterol } \\
\text { (mg/dl) }\end{array}$ \\
\hline G1 (11), before starvation & $26.47 \pm 4.96$ & $180.13 \pm 7.97$ & $0.87 \pm 0.01$ & $242.60 \pm 10.02$ & $5.29 \pm 0.99$ \\
\hline G2 (6), after starvation & $95.08 \pm 27.75$ & $162.25 \pm 13.30$ & $1.05 \pm 0.21$ & $221.75 \pm 7.44$ & $19.01 \pm 5.55$ \\
\hline P Value & $\mathrm{P}=0.01$ & NS & NS & NS & $P=0.01$ \\
\hline
\end{tabular}

NS: non-significant

Table 6. mean \pm SEM of lipid profile (total cholesterol, triglycerides, HDL cholesterol, LDL cholesterol, and VLDL cholesterol) in rats after starvation (G2) and during re-feeding (day 2 (G3), day 4 (G4), day 6 (G5) and day 8 (G6)).

\begin{tabular}{|c|c|c|c|c|c|}
\hline $\begin{array}{l}\text { Group }(n) / \\
\text { Variable }\end{array}$ & $\begin{array}{l}\text { Triglyceride } \\
\text { (mg/dl) }\end{array}$ & $\begin{array}{c}\text { Total } \\
\text { Cholesterol(mg/dl) }\end{array}$ & $\begin{array}{l}\text { LDL Cholesterol } \\
\text { (mg/dl) }\end{array}$ & $\begin{array}{l}\text { HDL Cholesterol } \\
\text { (mg/dl) }\end{array}$ & $\begin{array}{l}\text { VLDL } \\
\text { Cholesterol } \\
\text { (mg/dl) }\end{array}$ \\
\hline G2 (6) & $95.08 \pm 27.75$ & $162.25 \pm 13.30$ & $1.05 \pm 0.21$ & $221.75 \pm 7.44$ & $19.01 \pm 5.55$ \\
\hline G3 (10) & $101.34 \pm 15.44$ & $177.50 \pm 5.38$ & $0.970 \pm 0.08$ & $229.70 \pm 13.50$ & $20.26 \pm 3.09$ \\
\hline G4 (10) & $120.81 \pm 20.87$ & $187.10 \pm 4.79$ & $0.970 \pm 13.50$ & $238.60 \pm 14.81$ & $24.15 \pm 4.17$ \\
\hline G5 (9) & $97.50 \pm 16.23$ & $157.71 \pm 8.92$ & $0.75 \pm 0.04$ & $218.66 \pm 11.62$ & $19.50 \pm 3.24$ \\
\hline G6 (10) & $169.76 \pm 10.20 *$ & $196.38 \pm 5.44^{*}$ & $1.04 \pm 0.08$ & $250.50 \pm 6.88$ & $33.94 \pm 2.04^{*}$ \\
\hline
\end{tabular}

* Significant difference with group 2 (the effect of re-feeding), $P \leq 0.001$ 
Table 7. Intercorrelations (Pearson's) between evaluated physiological parameters.

\begin{tabular}{|c|c|c|c|c|c|c|c|c|c|c|}
\hline & & 1 & 2 & 3 & 4 & 5 & 6 & 7 & 8 & 9 \\
\hline 1 & MDA & 1 & & & & & & & & \\
\hline 2 & GPx & $-0.920 * *$ & 1 & & & & & & & \\
\hline 3 & SOD & $-0.905^{\star *}$ & $0.884^{* *}$ & 1 & & & & & & \\
\hline 4 & T4 & -0.148 & 0.179 & 0.102 & 1 & & & & & \\
\hline 5 & T3 & -0.224 & 0.263 & 0.205 & -0.019 & 1 & & & & \\
\hline 6 & VLDL- Cholesterol & -0.128 & 0.175 & 0.189 & 0.158 & 0.036 & 1 & & & \\
\hline 7 & HDL- Cholesterol & -0.246 & 0.232 & 0.238 & 0.067 & 0.192 & -0.010 & 1 & & \\
\hline 8 & LDL- Cholesterol & -0.186 & 0.134 & $0.335^{\star}$ & -0.101 & 0.027 & 0.203 & 0.163 & 1 & \\
\hline 9 & Total Cholesterol & $-0.457 * \star$ & $0.399 * *$ & $0.491 * *$ & -0.155 & 0.193 & 0.152 & $0.320 *$ & 0.226 & 1 \\
\hline 10 & Triglyceride & -0.118 & 0.164 & 0.182 & 0.157 & 0.035 & $1 * *$ & -0.013 & 0.208 & 0.150 \\
\hline
\end{tabular}

**. Correlation is significant at the 0.01 level (2-tailed); *. Correlation is significant at the 0.05 level (2-tailed).

may increase the MDA level [18]. In the present study, concentrations of SOD and GPx were decreased after starvation $(P \leq 0.001)$. The reduced level of antioxidant defenses and inadequate neutralization of reactive oxygen species (ROS) generated by sustained aerobic metabolism are consequences of starvation status $[19,20]$. Antioxidant response to cope with starvation is species-dependent, herein, studies on fish are scarce and a general or similar trend cannot be deduced [21]. The concentrations of GPx and SOD in day 2 (G3) and day 4 (G4) of refeeding status returned to the measured level before starvation status $(\mathrm{G} 1)$, respectively $(P>0.05)$. But the significant changes were seen in MDA level $(P \leq 0.05)$. Pro-oxidant effects of starvation status lasted for several days after resumption of refeeding status; it may be because of tissue oxidative injury or enhanced levels of T3, and hyper metabolic state [9]. Hyperthyroidism during refeeding was reported in anorexia nervosa by Rayment et al. [22]. T3 decreased significantly by starvation status $(\mathrm{P}<0.001)$. Warner and Beckett, (2010) stated that serum thyroid hormone levels will drop during starvation and severe illness [23]. A decrease in serum T3 levels can be seen in mild illness, and when the severity and length of the illness increases, both serum T3 and T4 will decrease. Anorexia Nervosa in human is associated with lower levels of thyroid hormones due to the effects of starvation status on metabolism [22]. In fact, starvation status results in a decrease in the serum T3 concentration due to decreased peripheral generation of T3 from T4 [24,25]. Carbohydrate is a major regulator of T4 deiodination [26]. Since starvation status resulted in decreased serum T3 concentrations and refeeding status is associated with an increase in serum T3 concentrations. This study demonstrates that starvation status induces increment in plasma triglyceride $(P=0.01)$, as well as enhanced level of VLDL cholesterol $(P=0.01)$. A similar pattern of plasma triglyceride elevation and enhanced level of VLDL in normal and non-obese human fasting for up to 9 days has been observed by Markel et al. [27]. Bernheimer et al. [28] also has shown an increase in triglyceride levels after starvation for six days in rabbits [28]. Enhanced level of VLDL cholesterol synthesis is due to increased free fatty acid available to the liver, and thus ketone bodies and VLDL cholesterols are secreted from the liver and utilized by extrahepatic tissues in starvation status [29]. Increased VLDL concentration 
Figure 1: Thyroid tissue of rats during the experiment, G1: before starvation; G2: after starvation, follicles with different sizes were seen $\left({ }^{*}\right)$ and the number of parafollicular cells were increased (arrow); G3: two days post-refeeding there were follicles with different sizes $\left(^{*}\right)$ and the number of parafollicular cells also were increased (arrow); G5: six days post-refeeding, follicles with different sizes were observed $(*)$, but the number of parafollicular cells were decreased (arrow); G6: eight days post-refeeding, follicles with different sizes were observed $\left({ }^{*}\right)$, but the number of parafollicular cells were decreased (arrow), H\&E, ×180.

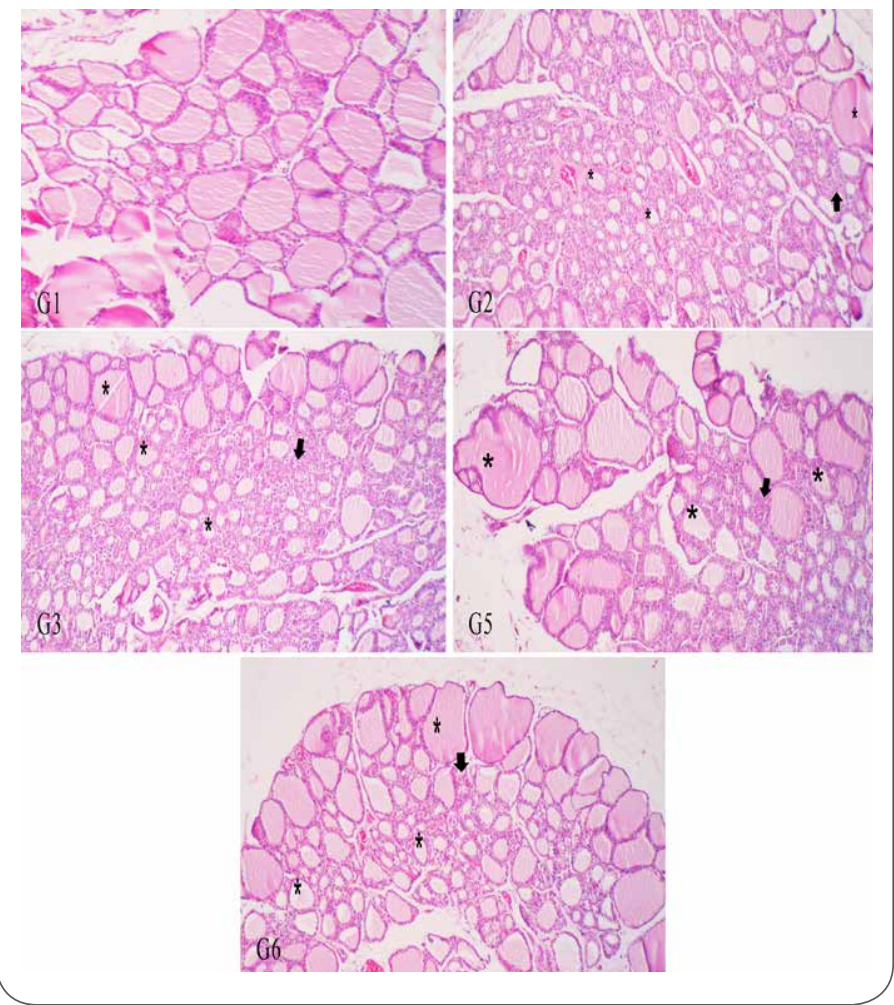

is important because it may have some role in the formation of atherogenesis [30]. There was a difference between obese subjects and normal nonobese subjects in the study undertaken by Markel et al. [27]. In obese subjects, starvation status occurred along with a reduction in plasma triglyceride and cholesterol concentrations. But, in normal subjects, starvation was observed along with elevation in plasma lipid levels. The observations of the present study were the same as the finding in non-obese fasted subjects. These findings are probably a result of the difference in tissue lipid content and response of testing rats to starvation status which was the same as non-obese subjects. Markel et al. [27] stated that the mobilization rate of free fatty acids is lower in obese normo-lipidaemic subjects than in non-obese normo-lipidaemic subjects [27]. Patient with anorexia nervosa showed increased plasma triglycerides, and total cholesterol [31]. In the present study, enhanced levels of plasma triglyceride, VLDL cholesterol and total cholesterol were observed in day 8 of refeeding status $(P \leq 0.05)$. Elevation in concentrations of these parameters may increase risk of atherosclerosis and cardiovascular diseases [32]. Many researchers have reported increased hepatic lipogenesis in starvation-refeeding status [33,34]. In addition, Wronska et al. [35] stated that increased sensitivity of adipose tissue to lipogenic stimuli is resulted from long-term calorie restriction [35]. Statistically significant negative correlation of MDA with GPx $(r=0.920, P<0.001)$ and SOD $(r=-0.905$, $\mathrm{P}<0.001)$ has been obtained in this study. Total cholesterol concentration correlated inversely with lipid peroxidation $(r=-0.457, P<0.001)$, while total cholesterol correlated positively with GPx $(r=0.399$, $P<0.001)$ and SOD $(r=0.491, P<0.001)$. The mechanism of free radical oxidation of cholesterol has been extensively studied [36]. These findings could indicate higher lipid peroxidation leading to lowering total cholesterol and consequently consumption and reduction in SOD and GPx concentration. Lipids in the body of vertebrates are stored and transported as triglycerides which are composed of glycerol with three fatty acid groups. The essential role of cholesterol is lipid transport [37]. VLDLcholesterol is made up of more triglycerides, and so estimated as one-fifth of the concentration of triglycerides [14], and their potent correlation is justified. In the present study, histopathological findings revealed a reduction in the amount of 
colloid secretion and the diameter of follicles and increase in the number of C-cells during starvation and then refeeding. Previous studies in mice and rabbits have also reported the decrease of follicles diameter and the amount of colloid secretion $[38,39]$. It might be that elevation in the number of parafollicular cells leads to stimulation of calcitonin secretion, resulting in inhibition of excessive bone resorption $[40,41]$.

\section{Conclusion}

Our results show that prolonged starvation leads to a pro-oxidant situation. The elevated level of plasma MDA and reduced activities of SOD and GPx can cause oxidative stress, which may play a critical role in the pathophysiology of starvation-refeeding syndrome. Starvation results in a decrease in the serum T3 concentration due to decreased peripheral generation of T3 from T4, because carbohydrates are major regulators of $\mathrm{T} 4$ deiodination. The increased free fatty acids availability to the circulation and eventually to the liver along with increased hepatic lipogenesis in starvation-refeeding status may contribute to increased VLDL synthesis and elevated plasma triglyceride levels. The negative effects of oxidative stress in considerable time after re-feeding should be considered in future studies.

\section{Acknowledgements}

The authors would like to thank the Research Council of Shiraz University and School of Veterinary Medicine, Shiraz University for financial and technical support of this study (Grant No.71-GR-VT-5).

\section{Conflicts of interest}

The authors declare that no competing interests exist.

\section{References}

1. Hearing SD. Refeeding syndrome. BMJ, 2004; 328(7445):908909.

2. Fuentebella J, Kerner JA. Refeeding syndrome. Pediatr Clin North Am, 2009; 56(5):1201-1210.
3. Khan LU, Ahmed J, Khan S, MacFie J. Refeeding syndrome: a literature review. Gastroenterol Res Pract, 2011; 1-6.

4. Obeid OA, Hachem DH, Ayoub JJ. Refeeding and metabolic syndromes: two sides of the same coin. Nutrition Diabetes, 2014; 4(6):e120.

5. Moyano D, Sierra C, Brandi N, Artuch R, Mira A, García-Tornel S, Vilaseca MA. Antioxidant status in anorexia nervosa. Int J Eat Disord, 1999; 25(1):99-103.

6. Furné M, García-Gallego M, Hidalgo MC, Morales AE, Domezain A, Domezain J, Sanz A. Oxidative stress parameters during starvation and refeeding periods in Adriatic sturgeon (Acipenser naccarii) and rainbow trout (Oncorhynchus mykiss). Aquacult Nutr, 2009; 15(6):587-595

7. Solmi M, Veronese N, Manzato E, Sergi G, Favaro A, Santonastaso $\mathrm{P}$, Correll CU. Oxidative stress and antioxidant levels in patients with anorexia nervosa: A systematic review and exploratory meta-analysis. Int J Eat Disord, 2015; 48(7):826-841.

8. Oliveras-López MJ, Ruiz-Prieto I, Bolaños-Ríos P, De la Cerda F, Martín F, Jáuregui-Lobera I. Antioxidant activity and nutritional status in anorexia nervosa: Effects of weight recovery. Nutrients, 2015; 7(4):2193-2208.

9. Venditti P, Di Meo S. Thyroid hormone-induced oxidative stress. Cell Mole Life Sci CMLS, 2006; 63(4):414-434.

10. Sundaram V, Hanna AN, Koneru L, Newman HAI, Falko JM. Both Hypothyroidism and Hyperthyroidism Enhance Low Density Lipoprotein Oxidation. J Clin Endocrinol Metab, 1997; 82(10):3421-3424

11. Baskol G, Atmaca H, Tanriverdi F, Baskol M, Kocer D, Bayram F. Oxidative stress and enzymatic antioxidant status in patients with hypothyroidism before and after treatment. Exp Clin Endocr Diab, 2007; 115(8):522-526.

12. Villanueva I, Alva-Sanchez C, Pacheco-Rosado J. The role of thyroid hormones as inductors of oxidative stress and neurodegeneration. Oxid Med Cell Longev, 2013; 2013:1-15.

13. Jain NC. 1986. Schalm's Veterinary Hematology. 4th ed. Lea and Febiger, Washington square, Philadelphia, USA. 1986.

14. Friedewald WT, Levy RI, Fredrickson DS. Estimation of the concentration of low-density lipoprotein cholesterol in plasma, without use of the preparative ultracentrifuge. Clin Chemist, 1972; 18(6):499-502.

15. Lata $H$, Ahuja GK, Narang AP. Effect of starvation stress on lipid peroxidation and lipid profile in rabbits. Indian J Physiol Pharmacol, 2002; 46(3):371

16. Pascual P, Pedrajas JR, Toribio F, López-Barea J, Peinado J. Effect of food deprivation on oxidative stress biomarkers in fish (Sparus aurata). Chem-Biol Interact, 2003; 145(2):191-199.

17. Bayir A, Sirkecioglu AN, Bayir M, Haliloglu HI, Kocaman EM, Aras NM. Metabolic responses to prolonged starvation, food restriction, and refeeding in the brown trout, Salmo trutta: Oxidative stress and antioxidant defenses. Comp Biochem Physiol B Biochem Mol Biol, 2011; 159(4):191-196.

18. Sorensen M, Sanz A, Gomez J, Pamplona R, Portero-Otin M, 
Gredilla R, Barja G. Effects of fasting on oxidative stress in rat liver mitochondria. Free Radical Res, 2006; 40(4):339-347.

19. Domenicali M, Caraceni P, Vendemiale G, Grattagliano I, Nardo B, Dall'Agata M, Bernardi M. Food deprivation exacerbates mitochondrial oxidative stress in rat liver exposed to ischemiareperfusion injury. J Nutr, 2001; 131(1):105-110.

20. Rahman K. 2007. Studies on free radicals, antioxidants, and cofactors. Clin Inter Aging, 2007; 2(2):219.

21. Morales $A E$, Pérez-Jiménez $A$, Furné $M$, Guderley $H$. Starvation, energetics, and antioxidant defenses. Oxid Stress Aqua Ecosys, 2012; 281-294.

22. Rayment D, Asfaha EA, Babiker A, Jaffa T. Hyperthyroidism during refeeding in anorexia nervosa. Int J Eat Disorder, 2012; 45(3):460-462.

23. Warner $\mathrm{MH}$, Beckett GJ. Mechanisms behind the non-thyroidal illness syndrome: an update. J Endocrinol, 2010; 205(1):1-13.

24. Harris AR, Fang SL, Vagenakis AG, Bravernan LE. Effect of starvation, nutriment replacement, and hypothyroidism on in vitro hepatic T 4 to T 3 conversion in the rat. Metabolism, 1973; 27(11):1680-1690.

25. Kelly G. Peripheral metabolism of thyroid hormones: a review. Altern Med Rev, 2000; 5(4):306-306.

26. Larsen PR, Berry MJ. Nutritional and hormonal regulation of thyroid hormone deiodinases. Annu Rev Nutr, 1995; 15(1):323-352.

27. Markel A, Brook JG, Aviram M. Increased plasma triglycerides, cholesterol and apolipoprotein $\mathrm{E}$ during prolonged fasting in normal subjects. Postgrad Med J, 1985; 61(715):395-400.

28. Bernheimer AW, Robinson WG, Linder R, Mullins D, Yip YK, Cooper NS, Uwajima T. Toxicity of enzymically-oxidized lowdensity lipoprotein. Biochem Biophys Res Commun, 1987; 148(1):260-266

29. Rui L. Energy metabolism in the liver. Compr Physiol 2014; 4:177197.

30. Carmena R, Duriez P, Fruchart JC. Atherogenic lipoprotein particles in atherosclerosis. Circulation, 2004; 109(23 suppl 1):III-2.

31. Zák A, Vecka M, Tvrzicka E, Hrubý M. Composition of plasma fatty acids and non-cholesterol sterols in anorexia nervosa. Physiol Res, 2005; 54(4):443.

32. Huffman DM, Barzilai N. Role of visceral adipose tissue in aging. Biochim Biophys Acta (DNLM), 2009; 1790(10):1117-1123.

33. Kochan Z, Karbowska J, Świerczyński J. Unusual increase of lipogenesis in rat white adipose tissue after multiple cycles of starvation-refeeding. Metabolism, 1997; 46(1):10-17.

34. Inai R, Matsuo T. Effect of Starvation-Refeeding Status on Cholesterol Metabolism in Rats Fed High-Cholesterol Diet. Food Nutr Sci, 2011; 2(02):118.

35. Wronska A, Sledzinski T, Goyke E, Lawniczak A, Wierzbicki P, $K$ miec Z . Short-term calorie restriction and refeeding differently affect lipogenic enzymes in major white adipose tissue depots of young and old rats. J Physiol Pharmaco, 2014; 65:117-126.
36. Xu L, Porter NA. Free radical oxidation of cholesterol and its precursors: Implications in cholesterol biosynthesis disorders. Free Radic Res, 2015; 49(7):835-849.

37. Pérez-Rodríguez L, Romero-Haro AA, Sternalski A, Muriel J, Mougeot F, Gil D, Alonso-Alvarez C. Measuring oxidative stress: the confounding effect of lipid concentration in measures of lipid peroxidation. Physiol Biochem Zool, 2015; 88(3):345-351.

38. Kmieć Z, Kotlarz G, Śmiechowska B, Myśliwski A. The effect of fasting and refeeding on thyroid follicule structure and thyroid hormone levels in young and old rats. Arch Gerontol Geriatr, 1998; 26(2):161-175.

39. Abdulla AG. Histological Effects of fasting and subsequent refeeding on thyroid follicles of rabbits morphometric analysis. Tikrit J Pure Sci, 2011; 16:12-16.

40. Kmieć Z, Kotlarz G, Myśliwski A, Wyrzykowska M, Pokrywka L. Thyroid $C$ cell function during fasting and refeeding of young and old rats. Folia Histochem Cytobiol, 2001; 40(2):185-186.

41. Swaminathan R, Bates RFL, Bloom SR, Ganguli PC, Care AD. The relationship between food, gastro-intestinal hormones and calcitonin secretion. J Endocrinol, 1973; 59(2):217-230.

Publish in International Archives of Medicine

International Archives of Medicine is an open access journal publishing articles encompassing all aspects of medical science and clinical practice. IAM is considered a megajournal with independent sections on all areas of medicine. IAM is a really international journal with authors and board members from all around the world. The journal is widely indexed and classified Q2 in category Medicine. 